\title{
Persistent Educational Advantage Across Three Generations: Empirical Evidence for Germany
}

\author{
Andrea Ziefle \\ Goethe-University Frankfurt am Main
}

Abstract: This article uses survey data from the German Socio-Economic Panel (GSOEP) to analyze the persistence of educational attainment across three generations in Germany. I obtain evidence of a robust effect of grandparents' education on respondents' own educational attainment in West Germany, net of parental class, education, occupational status, family income, parents' relationship history, and family size. I also test whether the grandparent effect results from resource compensation or cumulative advantage and find empirical support for both mechanisms. In comparison, the intergenerational association between grandparents' and respondents' education is considerably weaker in East Germany and is also mediated completely by parental education. There are hardly any gender differences in the role of grandparents for respondents' educational attainment, except for the fact that resource compensation is found to be exclusively relevant for women's attainment in both West Germany and in East Germany after German reunification and the associated transition to an open educational system.

Keywords: educational attainment; social mobility; inequality of educational opportunity; intergenerational transmission; multigenerational effects; cultural capital

Citation: Ziefle, Andrea. 2016. "Persistent Educational Advantage Across Three Generations: Empirical Evidence for Germany." Sociological Science 3: 10771102.

Received: September 14, 2016

Accepted: October 6, 2016

Published: December 12, 2016

Editor(s): Jesper Sørensen, Kim Weeden

DOI: $10.15195 / \mathrm{v3} . \mathrm{a} 47$

Copyright: (C) 2016 The Author(s). This open-access article has been published under a Creative Commons Attribution License, which allows unrestricted use, distribution and reproduction, in any form, as long as the original author and source have been credited. (C) (i)
$T^{\mathrm{N}}$ an influential article, Mare (2011) stated the case for a multigenerational per1 spective on inequality of educational and status attainment: given the many modes of social influence between members of the extended family other than parents and their own children, the traditional two-generation study of the association between parents' and children's attainment is likely to underestimate the total effect of family background on attainment and the extent of continuity in socioeconomic status within family lineages in modern societies (cf. also Jæger 2012; Mare 2014, 2015; Pfeffer 2014; and Solon 2014 for similar recent statements). Even as the central role of the transmission of resources between parents and children is undisputed, it does not follow that the intergenerational transmission of advantage occurs only between parents and their own children (i.e., is "Markovian" in the terminology of Mare). Grandparents and other members of the extended family may influence children's educational or occupational aspirations through their own regular interactions with them, they might take on an active role in caregiving and parenting that affects children's schooling performance directly through supervision of homework and other forms of social support, or they might be a source of additional economic, cultural, or social resources over and above what parents are able to provide within the nuclear family themselves. In any of these cases, however, the traditional parent-child associations will underestimate the true role of family background for attainment and will portray societies as more open than they actually are. 
As multigenerational data are becoming increasingly available, sociologists and other social scientists have begun to respond to Mare's (2011) call for multigenerational empirical research on social stratification, and as new data is being analyzed and older data is being reexamined, this new wave of empirical research is likely to contribute to a more refined understanding of when, where, and how extended families matter for attainment. Up until quite recently, Warren and Hauser's (1997) landmark study would have been considered a prime empirical confirmation of a "Markovian" model of intergenerational transmission and the resulting focus on parent-child associations in status attainment. Yet, while Warren and Hauser (1997) unambiguously concluded that grandparents had no independent effects on respondents' attainment once parental resources had been controlled for, the general validity of their conclusions is called into question by more recent research that either reexamines the U.S. case or that extends the reach of multigenerational analysis to other countries.

Using the Panel Study of Income Dynamics (PSID) and the National Longitudinal Survey of Youth (NLSY) data instead of the Wisconsin Longitudinal Survey (WLS) that Warren and Hauser (1997) had relied upon, Jæger (2012) as well as Wightman and Danziger (2014) confirm Warren and Hauser's (1997) core conclusion about the absence of net grandparent effects on children's attainment, whereas both Pfeffer (2014) and Hertel and Groh-Samberg (2014) report net grandparent effects on both educational attainment and respondents' class position. Even more strikingly, Jæger (2012), Pfeffer (2014), Hertel and Groh-Samberg (2014) as well as Wightman and Danziger (2014) all agree that grandparent effects are not uniform across social strata and that net grandparent effects are in fact present in the tails of the (parental or grandparental) status distribution. Consistent with a theory of compensating resources, Jæger (2012) and Wightman and Danziger (2014) report net grandparent effects on educational attainment among respondents from low-socioeconomic status (SES) households. Pfeffer (2014) and Hertel and GrohSamberg (2014) also find nonlinear effects but report grandparent net effects that occur at both ends of the status distribution. Moving beyond the United States, current research has produced mixed empirical results but in fact mostly leans towards findings of net grandparent effects on attainment. Net grandparent effects on educational or occupational attainment have been reported for such a diverse set of countries as Denmark, Finland, Germany, Sweden, and the United Kingdom (Chan and Boliver 2013, 2014; Modin, Erikson, and Vadero 2013; Hällsten 2014; Hertel and Groh-Samberg 2014; Lindahl et al. 2015; Møllegaard and Jæger 2015; but cf. Erola and Moisio 2007 for negative results in case of Finland), Zeng and Xie (2014) reported conditional net grandparent effects (for coresident grandparents only) for China, and only Bol and Kalmijn (2016) found no grandparent effects on attainment for the Netherlands after controlling for parental characteristics.

As another country case study in this burgeoning field of research, the present article reports on the results of an analysis of intergenerational persistence in educational attainment across three generations in Germany, where respective research has been scarce so far. By looking at educational attainment, my analysis complements Hertel and Groh-Samberg's (2014) recent study of three-generation class mobility among West German men and also obtains evidence of a robust net effect 
of grandparents' education on respondents' own educational attainment. I then follow the lead of Jæger's (2012) and Wightman and Danziger's (2014) research on the United States, and I am able to confirm resource compensation as one mechanism behind net grandparent effects on educational attainment in Germany. However, unlike in the U.S. case, I also find evidence for cumulative advantage as a second mechanism that generates net grandparent effects on attainment among high-SES families in Germany. In addition, unlike Hertel and Groh-Samberg's (2014) earlier study on class mobility, I incorporate data on East German respondents in order to examine three-generation persistence in educational attainment under the former German Democratic Republic's (GDR) socialist education system and also to provide evidence on whether there have been any changes with respect to multigenerational effects on attainment after German reunification. Finally, my study is also the first to systematically explore potential gender differences in the role of grandparents for attainment in Germany.

\section{Theoretical Background}

\section{A Review of Current Research}

The study of multigenerational processes of attainment is a natural extension of traditional two-generation models of status attainment. Like in standard twogeneration models, multigenerational models proceed from the assumption that (various kinds of) family resources matter for educational or occupational attainment (e.g., Blau and Duncan 1967; Jencks et al. 1972; Bourdieu 1977; Becker and Tomes 1986), yet unlike the traditional model, multigenerational approaches do not restrict themselves to the assumption that intergenerational transmission of resources would occur exclusively through the parent-child relationship (cf. Mare 2011, 2014, 2015; Jæger 2012; Pfeffer 2014; Solon 2014). The distinctive feature of the recent multigenerational attainment research is not, however, that grandparents are thought to matter for attainment but rather how. In the traditional two-generation setup, the implicit theoretical assumption is that the intergenerational transmission of advantage features the "Markovian" (Mare 2011) property of lack of memory: multigenerational attainment processes can, in other words, be represented as a sequence of multiple parent-child transmission chains because at each transmission cycle, data on prior generations is no longer informative once the characteristics of parents have been considered. Another way of expressing the same assumption would be to state that grandparents surely are important for the educational and occupational attainment of their grandchildren, but they are so only because of the investments they made in their own children that, a generation later, have then become embodied as the resources that the parent generation passes on to their children. If grandparent influences exceed this particular level of intergenerational transmission, then multigenerational status attainment can be termed "non-Markovian".

In fact, a string of recent studies from countries like Denmark, Finland, Germany, Sweden, and the United Kingdom (Chan and Boliver 2013, 2014; Modin et al. 2013; Hällsten 2014; Hertel and Groh-Samberg 2014; Lindahl et al. 2015; Møllegaard 
and Jæger 2015) that all support a "non-Markovian" model of multigenerational attainment by now almost make the original U.S. findings of Warren and Hauser (1997), Jæger (2012), or Wightman and Danziger (2014) an outlier in comparison to other countries. Besides the U.S. case, there is only Zeng and Xie's (2014) study on rural China and Bol and Kalmijns' (2016) research on the Netherlands that likewise find no net grandparent effects on educational attainment once parental resources have been controlled for. And even for the U.S. case, all of the recent studies agree that despite mostly finding no net grandparent effects overall (but cf. Pfeffer 2014; Hertel and Groh-Samberg 2014 for exceptions), net grandparent effects occur in the tails of the parental SES distribution. Both Jæger (2012) and Wightman and Danziger (2014) report net grandparent effects on educational attainment among respondents from low-SES and low-income households, respectively. Pfeffer (2014) and Hertel and Groh-Samberg (2014) even find net grandparent effects at both the upper and lower ends of the (parental) education and class distributions.

The evidence on grandparent effects among low-SES parents clearly suggests that resource compensation is one key mechanism for how grandparents affect attainment over and above a Markovian two-generation model (cf. Jæger 2012 in particular). That is, grandparents are evidently able to provide additional support specifically when parents lack essential resources to advance children's attainment, whether because they involve themselves more actively in parenting and childrearing or whether they directly or indirectly transfer the required economic, cultural, or social resources to their grandchildren. As a result of resource compensation, children whose parents experienced downward educational, status, or class mobility relative to the grandparent generation are likely to see higher educational or status attainment outcomes than their peers from similar parental backgrounds who lack access to the extra resources available from high-status grandparents.

The recent findings of broader grandparent effects on educational or occupational attainment for a number of European countries suggest a more general pattern of grandparent influence, however. If, as has been empirically confirmed by now for Denmark, Finland, Germany, Sweden, and the United Kingdom (Chan and Boliver 2013, 2014; Modin et al. 2013; Hällsten 2014; Hertel and Groh-Samberg 2014; Lindahl et al. 2015; Møllegaard and Jæger 2015), there is a positive grandparent effect in the population on average, grandparent resources obviously play a more important role in the intergenerational transmission process than only as compensation in times of hardship. As Mare (2011, 2014), Jæger (2012), Møllegaard and Jæger (2015), Bol and Kalmijn (2016), and others argue, there is in fact little reason why the influence of grandparents should be via parents' own resources only. Over and above any support provided to their own children, grandparents may affect educational and occupational aspirations of their grandchildren through their regular interactions with them, or they may assume direct responsibility for their educational success by sharing some of the tasks in childrearing with parents. So far, there seems to be little empirical support for the idea that successful multigenerational transmission would depend on the quality of the personal relationship between grandparents and their grandchildren, as neither the analyses of Jæger (2012) using U.S. data nor those of Bol and Kalmijn (2016) for the Netherlands yielded any positive evidence. Zeng and Xie's (2014) research on rural China instead suggests that geographical proximity 
may matter more, up to the point of multigenerational transmission occurring only for coresident grandparents in their study. Moreover, the evidence in both Jæger (2012) and Møllegaard and Jæger (2015) indicates that multigenerational advantage occurs mostly through cultural transmission, as they obtained the strongest effects for grandparents' level of education in both U.S. and Danish data.

In line with the prominent role of cultural capital in multigenerational transmission, findings of pronounced grandparent effects at the upper tails of the (parental) educational or class distribution in Germany, Sweden, and the United States (cf. Pfeffer 2014; Hertel and Groh-Samberg 2014; Lindahl et al. 2015) might indicate the presence of mechanisms other than resource compensation. Upper-class persistence of educational or class attainment may signal a special role for family wealth as a determinant of attainment (Pfeffer 2011), as wealth is significantly more unequally distributed than family income, education, or status, and it may thus be a specific predictor of access to high-cost elite educational institutions. On a more cultural interpretation, however, it is also plausible that upper-class persistence results from a process of cumulative advantage (DiPrete and Eirich 2006), in which the positive effects of parental education and cultural capital are enhanced when being embedded in a broader family environment (of grandparents and other members of the extended family) that is rich in cultural capital itself. This process of cultural cumulative advantage resonates with Lindahl et al.'s (2015) idea of "dynastic" capital but could of course also be expressed in Bourdieu's (1977) terminology as an educational family "habitus" that characterizes an attitude of self-evident educational achievement in families with a lineage of academics. In either case, such a process of cumulative advantage would disproportionately generate net grandparent effects at the top end of the parental education or class distribution because that is where parental and the wider family's resources are able to reinforce each other.

\section{Hypotheses}

In the following analysis, I will also focus on the educational side of multigenerational persistence in attainment. As a baseline hypothesis of the analysis, I predict that:

Hypothesis 1 (multigenerational status attainment): Grandparents' (G1) education has a positive effect on children's (G3) educational attainment in Germany, net of parental (G2) resources and socioeconomic status.

This baseline hypothesis follows directly from the general assumption in the multigenerational literature that individuals benefit from economic, cultural, and social resources available in the wider family so that intergenerational transmission is not necessarily restricted to processes occurring within nuclear families between parents and children. For Germany specifically, the principal presence of multigenerational effects is suggested by Hertel and Groh-Samberg's (2014) recent study of three-generation class mobility; related empirical evidence of multigenerational effects on educational attainment has in fact also been an unnoticed byproduct in an exchange between Fuchs and Sixt (2007a, 2007b) and Becker (2007) on the 
sustainability of upward educational mobility across three generations. In what follows, I will extend these earlier studies by adding more recent data from the GSOEP and by systematically comparing multigenerational effects on educational attainment among East and West German respondents as well as between men and women in both parts of the country.

Any positive evidence of multigenerational effects on educational attainment results in the question of which mechanisms might be responsible for them. To probe these, I first follow the lead of Jæger (2012) and predict that:

Hypothesis 2 (multigenerational resource compensation): Grandparent (G1) resources support children's (G3) educational attainment by compensating for deficient economic, cultural, or social resources available in the nuclear (G2) family. By implication, children (G3) of downwardly mobile parents (G2 level of education $<$ G1 level of education) will achieve more positive educational outcomes than other children at the same level of parental (G2) education.

In addition, it is also plausible that cultural capital available in both the nuclear and the extended family is mutually reinforcing in its positive effects on children's educational attainment. This yields:

Hypothesis 3 (multigenerational cumulative advantage): Grandparent (G1) resources support children's (G3) educational attainment by enhancing the value of economic, cultural, or social resources available in the nuclear (G2) family itself. By implication, children (G3) of upwardly mobile parents (G2 level of education > G1 level of education) will achieve less positive educational outcomes than other children at the same level of parental (G2) education.

Taken together, hypotheses 2 and 3 can explain recent empirical findings about multigenerational persistence occurring specifically in the tails of the (parental) status distribution, whether at the lower end as found by Jæger (2012) and Wightman and Danziger (2014) in the United States., at the upper end as reported in Lindahl et al. (2015) for Sweden, or even at both ends (cf. Pfeffer 2014; Hertel and Groh-Samberg 2014 for Germany and the United States). That is to say, multigenerational resource compensation explains the existence of (strong) grandparent effects in the lower tail of the (parental) educational or status distribution because that is where downwardly mobile parents will disproportionately be located in their own (G2) generation's distribution. Multigenerational cumulative advantage in turn explains (strong) grandparent effects in the upper tail of the (parental) educational distribution, as that is where academic dynasties will be located in their own (G2) generational distribution. Multigenerational persistence at either end of the status distribution may well be caused by other social mechanisms than family education-parental wealth underlying upper-class persistence, for example-but hypothesis 2 and hypothesis 3 detail those two mechanisms of cultural resource compensation and cultural cumulative advantage that will specifically be tested with the subsequent empirical analysis. 
Within this broad framework of multigenerational persistence in educational attainment, Germany actually represents a particularly interesting test case given the country's political history over the twentieth century. While the former Federal Republic (FRG) naturally falls in line with the United States and other liberal societies in terms of stratification and attainment, the East German GDR represented the deliberate attempt to create a socialist society out of the ruins of Nazi Germany and World War II. Prior to reunification in October 1990, this very much included state socialist educational policies strictly focused on equality of opportunity in terms of providing educational opportunity for working-class children as well as gender equality in access to education and training (Geißler 1983, 1990, 2011). Other features of the state socialist educational system were the strict planning of educational trajectories that limited family choice about access to upper-level secondary and higher education at the micro level and that prevented any expansion of higher education at the system level, especially since the 1970s (Mayer and Solga 1994; Huinink and Solga 1994; Geißler 2011). Since about the same time, political allegiance to the socialist regime also became a noticeable factor in admission to upper secondary and university education (Huinink and Solga 1994; Geißler 2011). Taken together, the systemic differences between East and West Germany suggest:

Hypothesis 4 (weak multigenerational attainment in East Germany): The GDR's socialist educational policies restricted families' effectiveness in transmitting resources to affect children's (G3) educational attainment across generations relative to the FRG's open educational system. By implication, this extends to multigenerational effects between grandparents (G1) and children (G3).

In that context, the historic event of German reunification in 1990 in fact provides yet another informative contrast. Because the data of the present analysis include East German respondents who entered secondary education (the decisive stage in Germany's tracked schooling system) prior to reunification as well as respondents who entered secondary schooling after reunification, it is possible to observe potential (relatively sudden) changes in multigenerational educational attainment after the removal of state socialist restrictions on educational trajectories. If socialist policies of either planned access to higher education or political restrictions on higher education entry were relevant, one might expect:

Hypothesis 5 (increasing multigenerational attainment in East Germany after reunification): With the transition to an open educational system after German reunification, family leverage to affect children's educational outcomes should have increased. By implication, this extends to multigenerational effects between grandparents (G1) and children's (G3) educational attainment. 


\section{Data and Methods}

\section{Data}

For the subsequent empirical analysis, I use survey data from the German SocioEconomic Panel (GSOEP) for the years 1984-2013 (survey waves A-BD). The GSOEP was started in former West Germany in 1984, was extended to East Germany immediately after German reunification in 1990, and has now been in continuous operation as an annual panel survey that is representative of the residential population in Germany for more than 30 years (Wagner, Frick, and Schupp 2007). The GSOEP collects a wealth of information on respondents' family background, and with the maturation of the survey this information on social background can now be linked across three generations (cf. the earlier studies of Fuchs and Sixt 2007a, 2007b; Hertel and Groh-Samberg 2014 for similar approaches). As a household survey, the GSOEP intends to trace the life course of every member of a survey household and retains respondents as members of the survey's target sample even after the original survey household may have dissolved. For all respondents whose family of origin has already been a GSOEP survey household, it is therefore possible to construct a three-generation mobility dataset (even as children may have moved out of the parental home) from linking the information on grandparents' (G1) socioeconomic status that was retrospectively collected in the parent (G2) generation to the records of the children (G3) generation. As a result, the intergenerational GSOEP dataset combines prospectively collected data on current (G3) generation outcomes with information on parents' (G2) socioeconomic status that is collected through both retrospective and prospective survey elements and retrospective information on grandparents' (G1) socioeconomic status collected in parent (G2) generation survey interviews (cf. Mare 2015 for an extended discussion of the advantages and disadvantages associated with alternative multigenerational data structures).

For the present analysis, I construct such a three-generation dataset from the GSOEP that includes all GSOEP respondents from birth cohorts 1967-1992 who have participated in the GSOEP up until at least their 21st birthday and for whom at least one parent has been a GSOEP respondent. ${ }^{1}$ This choice of sample allows me to observe children's (G3) educational outcomes up until the completion of upper secondary education (Abitur), which is usually taken at ages 18 or 19 and which corresponds to the key branching point between academic and nonacademic trajectories in Germany's tracked educational system. Setting a sufficient age threshold to also observe the eventual completion of a university degree would reduce the available sample size by about half in the present context and is therefore not pursued further. Implicitly, it is in fact safe to assume that the broad majority of German students who complete an Abitur degree will also move on to some type of tertiary education studies and eventually complete a tertiary degree. For the current sample, fully 77 percent of all Abitur degree holders have taken up some form of tertiary education by age 21 , and this number is even 83 percent in the (smaller) sample of respondents who have already reached age 25 at the point of their last survey interview.

In line with its decisive role in the German educational system, I use the probability that current (G3) generation respondents complete upper secondary education 
(i.e., hold an Abitur degree) as the dependent variable of the analysis. To address intergenerational educational persistence, I record grandparents' (G1) and parents' (G2) level of education as measured by the CASMIN scale (Braun and Müller 1997; Brauns and Steinmann 1999). For grandparents, I use the highest level of education of any of the four grandparents on both the maternal and the paternal family side. ${ }^{2}$ For parents, I also define the highest level of education within the nuclear family and include mother's level of education as an additional mediator. Besides parental education, the analyses incorporate measures of parental social class, parental occupational status, family disposable income, parents' relationship history, and family size as potential mediators of the association between grandparents' (G1) level of education and respondents' (G3) educational attainment.

For parental social class, I derive an eight-category measure that proxies the well-known EGP class scheme from a direct survey question on respondents' class position ("berufliche Stellung"), as this results in considerably fewer missing values than using the actual EGP scheme based on the detailed occupational data. Parental occupational status is measured as the highest score of either the father's or the mother's detailed occupation on the International Socio-Economic Index (ISEI) (cf. Ganzeboom and Treiman 1996). For family income, I first convert all income data as relative to the median equivalent income in any given year and then compute the average household net equivalent disposable income in the family of origin in respondents' youth and adolescence (i.e., while respondents had been between 11 and 20 years old). ${ }^{3}$ In addition, I use the proportion of years that respondents were living with both parents between the ages of 6-18 as an indicator of parental (G2) family stability during respondents' childhood and adolescence, and I also record the number of siblings as an indicator of family size. At the respondent (G3) level, all analyses furthermore control for gender, parity status, immigration status ( $1^{\text {st }}$ and $2^{\text {nd }}$ generation migrants vs. autochthonous majority population), and the region (East vs. West Germany) that respondents were growing up in. ${ }^{4}$ For all parental covariates other than education, I also define missing value indicators to be included in the statistical models as technical variables to ensure a consistent and reasonably large sample size for analysis. ${ }^{5}$ Appendix Table 1 in the online supplement provides the descriptive statistics for all the covariates used in the analysis.

\section{Statistical Analysis}

Under these restrictions, I retain a multigenerational sample of around 6,400 GSOEP respondents from birth cohorts 1967-1992, for whom there is valid information on their own (G3) educational attainment by age 21, their parents' (G2) educational attainment, as well as their grandparents' (G1) level of education and all other covariates as defined before. ${ }^{6}$ For this sample, I analyze the probability of attaining upper secondary education (i.e., an Abitur degree) using binary logistic regression models. I first estimate the gross association between grandparents' (G1) education and respondents' (G3) educational outcomes from a model that excludes any parental (G2) generation covariates and then include them in a second step in order to estimate the net (multigenerational) grandparental influence on respondents' 
educational attainment, controlling for mediation via parental resources. ${ }^{7}$ In an earlier analysis, Fuchs and Sixt (2007a, 2007b) obtained evidence of multigenerational effects when only parental education was controlled for but insignificant grandparent effects in the full model that included occupational prestige, family income, levels of education for both partners, and an additional measure of cultural capital. As a potential replication, I present evidence from two variants of the net multigenerational model, in which I first control for (both) parents' education only and then add the full set of parental (G2) generation controls in a second variant. I conduct all analyses separately for the East and West German sample and also provide gender-specific results to explore potential gender differences in the importance of grandparents for attainment. ${ }^{8}$ Finally, I also conduct separate analyses for East German respondents who entered secondary schooling either before or after German reunification in order to test for the presence of institutional constraints on the multigenerational persistence of educational attainment in the former GDR's state socialist educational system.

To further examine the mechanisms behind multigenerational attainment processes, I then test whether the observed multigenerational effects on educational attainment result from either resource compensation, cumulative cultural advantage, or both. This test builds on the fact that data on educational mobility between the grandparent and parent (G1-G2) generation provides a measure of the (superior) cultural capital of the extended family that may affect educational attainment in the respondent (G3) generation. If multigenerational resource compensation is a relevant mechanism, the returns to downward educational mobility in the G2 generation (in terms of G3 attainment) will be less negative than if the family had been at the G2 level of education in both (G1 and G2) generations because grandparents will be able to provide superior cultural resources to help respondents' (G3) attainment in the former constellation but not in the latter. Upward educational mobility in the parental (G2) generation will, in turn, be informative about the presence of dynastic cultural capital resulting in cumulative advantage for respondents' (G3) educational trajectories. If the (G3) returns to parental (G2) educational resources are higher in established, well-educated (G1-G2) families than in families in which parents have been upwardly mobile to reach their G2 level of education, then cultural resources that are available in the extended family are mutually reinforcing in their positive impact on respondents' (G3) attainment.

\section{Empirical Results}

\section{Multigenerational Persistence in Educational Attainment in Germany}

As a first step in the analysis, I explore whether there is empirical evidence of multigenerational effects on respondents' educational attainment in Germany. Table 1 has the relevant results from a first series of logistic regression models that relate respondents' (G3) probability of obtaining the Abitur degree to grandparents' (G1) educational resources as well as parents' (G2) socioeconomic characteristics. In the first model of Table 1 (model A), I estimate the gross association between grandparent (G1) education and respondents' (G3) educational outcomes, while 
Table 1: The association between grandparents' (G1) level of education and respondents' (G3) probability of obtaining upper secondary schooling (Abitur degree) in Germany, birth cohorts 1967-1992, logistic regression models.

\begin{tabular}{|c|c|c|c|c|c|c|}
\hline & All & Daughters & Sons & All & Daughters & Sons \\
\hline & \multicolumn{3}{|c|}{ b (standard error) } & \multicolumn{3}{|c|}{$\begin{array}{l}\text { Average marginal effects } \\
\text { (standard error) }\end{array}$} \\
\hline & \multicolumn{6}{|c|}{ (A) Gross G1-G3 association, without G2 controls } \\
\hline \multirow[t]{2}{*}{ West Germany, cohorts 1967-92 } & $0.255^{\dagger}$ & $0.255^{\dagger}$ & $0.255^{\dagger}$ & $0.053^{\dagger}$ & $0.053^{+}$ & $0.052^{+}$ \\
\hline & $(0.017)$ & $(0.024)$ & $(0.022)$ & $(0.003)$ & $(0.005)$ & $(0.004)$ \\
\hline \multirow[t]{3}{*}{ East Germany, cohorts 1973-92 } & $0.159^{\dagger}$ & $0.181^{\dagger}$ & $0.142^{+}$ & $0.035^{\dagger}$ & $0.041^{+}$ & $0.031^{\dagger}$ \\
\hline & $(0.027)$ & $(0.038)$ & $(0.036)$ & $(0.006)$ & $(0.008)$ & $(0.007)$ \\
\hline & \multicolumn{6}{|c|}{ (B) Net G1-G3 association, controlling for G2 education } \\
\hline \multirow[t]{2}{*}{ West Germany, cohorts 1967-92 } & $0.075^{\dagger}$ & $0.067^{*}$ & $0.081^{\dagger}$ & $0.014^{+}$ & $0.012^{*}$ & $0.015^{+}$ \\
\hline & $(0.020)$ & $(0.029)$ & $(0.025)$ & $(0.004)$ & $(0.005)$ & $(0.005)$ \\
\hline \multirow[t]{3}{*}{ East Germany, cohorts 1973-92 } & 0.039 & 0.049 & 0.031 & 0.007 & 0.009 & 0.006 \\
\hline & $(0.030)$ & $(0.044)$ & $(0.038)$ & $(0.006)$ & $(0.008)$ & $(0.007)$ \\
\hline & \multicolumn{6}{|c|}{ (C) Net G1-G3 association, controlling for full G2 covariates } \\
\hline \multirow[t]{2}{*}{ West Germany, cohorts 1967-92 } & $0.053^{\dagger}$ & 0.044 & $0.059^{*}$ & $0.009^{+}$ & 0.008 & $0.010^{*}$ \\
\hline & $(0.020)$ & $(0.028)$ & $(0.026)$ & $(0.004)$ & $(0.005)$ & $(0.005)$ \\
\hline \multirow[t]{2}{*}{ East Germany, cohorts 1973-92 } & 0.003 & 0.000 & -0.001 & 0.001 & 0.000 & -0.000 \\
\hline & $(0.032)$ & $(0.050)$ & $(0.041)$ & $(0.006)$ & $(0.008)$ & $(0.007)$ \\
\hline N, West Germany & 5,161 & 2,414 & 2,747 & & & \\
\hline N, East Germany & 1,243 & 585 & 658 & & & \\
\hline
\end{tabular}

Notes: full G2 covariates = highest level of parental education, mother's level of education, parental social class, highest occupational status (ISEI) in family, average family income level in respondents' youth, fraction of time respondents were living with both parents, number of siblings, missing value indicators for all covariates except parental education. All models control for full gender and birth cohort interactions, parity, and immigration status.

Cluster-corrected standard errors in parentheses; $\uparrow p<0.01 ; * p<0.05$.

Source: GSOEP 1984-2013.

the second model (model B) provides a first estimate of net grandparent effects controlling for parental (G2) education, and the third model (model C) provides the second variant of net grandparent effect estimates that incorporate the full vector of parent (G2) characteristics. All three models are estimated separately for East and West German respondents, as well as separately for sons and daughters within either region.

Model A shows a statistically and substantially significant association between grandparents' (G1) resources and respondents' (G3) educational outcomes in both parts of Germany. Expressed in terms of the implied average marginal effect (AME), the probability of obtaining the Abitur degree increases by more than five percentage points for each level of education on the CASMIN scale that grandparents have been able to attain in West Germany and still 3.5 percentage points per level of grandparents' education in East Germany. ${ }^{9}$ Moreover, there is no evidence of 
any gender difference in the importance of grandparents, as the estimated effects are exactly equal for both sons and daughters in the current (G3) generation in West Germany and slightly_but not significantly_different between sons and daughters in the East German sample. The difference between East and West Germany is meaningful and statistically significant, however. As a first confirmation of hypothesis 4, the gross association between grandparents' and respondents' level of education is stronger in West Germany than in East Germany.

The same regional pattern is evident in models B and C of Table 1 that report my estimates of grandparent effects net of any mediating effects of parental (G2) resources. Irrespective of whether I control for parental education only (model B) or for the full set of parent-level controls available in the analysis (model C), the estimated effects are always larger among West German respondents than among East German ones, and these differences are statistically significant. In fact, the results provide no convincing evidence for any kind of multigenerational (nonMarkovian) influence of grandparents in East Germany at all. After controlling for parental education (in model B), a small positive effect of grandparent education remains (in the order of an AME of +0.7 percentage points per CASMIN level), but the effect is no longer statistically significant. In model $C$, when all parental (G2) characteristics are being controlled for, there is no net effect of grandparent resources at all.

In contrast, multigenerational attainment is evident in the West German sample, confirming both hypothesis 1 and earlier results of Hertel and Groh-Samberg (2014) for the attainment of class positions. Accounting for the intergenerational transmission between grandparents' (G1) and parents' (G2) education still results in a net grandparent effect in the order of an AME of +1.5 percentage points per level of grandparent education (in model B), and this effect is further reduced somewhat (to an AME of +1 percentage point per level of grandparent education) but not completely eliminated by the full set of parent-level controls in model C. Multigenerational effects on attainment appear to be about equally relevant for men and women in the West German sample in substantive terms, although the estimate marginally fails to reach conventional levels of statistical significance among women in the final model (model C). The full set of coefficient estimates from the final model is documented in Table 2 but not discussed further at this point. The empirical estimates for parental education, class, or family income effects correspond to standard findings in the German and international literature on educational inequality.

\section{Mechanisms of Multigenerational Persistence: Resource Compensation, Cumulative Advantage, or Both?}

Given the evidence on multigenerational patterns of attainment (at least for West Germany), it is of interest to examine whether resource compensation or cumulative advantage might be mechanisms that generate the net effects of grandparent resources on current generation educational attainment. As was discussed before, educational mobility in the parental generation (i.e., G1-G2 mobility) is a critical indicator of the cultural resources available in respondents' extended family. Where 
Table 2: The association between grandparents' (G1) level of education and respondents' (G3) probability of obtaining upper secondary schooling (Abitur degree) in Germany, birth cohorts 1967-1992, logistic regression models.

\begin{tabular}{|c|c|c|c|c|c|c|}
\hline & \multicolumn{3}{|c|}{ West Germany, cohorts 1967-92 } & \multicolumn{3}{|c|}{ East Germany, cohorts 1973-92 } \\
\hline & All & Daughters & Sons & All & Daughters & Sons \\
\hline G: Highest level of education & $0.053^{\dagger}$ & 0.044 & $0.059 *$ & 0.004 & 0.000 & -0.001 \\
\hline$(\mathrm{CASMIN})$ & $(0.020)$ & $(0.028)$ & $(0.026)$ & $(0.032)$ & $(0.050)$ & $(0.041)$ \\
\hline P: Highest level of education & $0.172^{\dagger}$ & $0.147^{\dagger}$ & $0.202^{\dagger}$ & $0.264^{+}$ & $0.266^{\dagger}$ & $0.261^{\dagger}$ \\
\hline$(\mathrm{CASMIN})$ & $(0.027)$ & $(0.038)$ & $(0.035)$ & $(0.068)$ & $(0.095)$ & $(0.097)$ \\
\hline P: Mother's level of education & $0.120^{\dagger}$ & $0.174^{\dagger}$ & 0.070 & 0.093 & 0.148 & 0.058 \\
\hline (CASMIN) & $(0.029)$ & $(0.041)$ & $(0.037)$ & $(0.059)$ & $(0.090)$ & $(0.080)$ \\
\hline \multicolumn{7}{|c|}{ P: Social class (Ref.: managers, firm owners) } \\
\hline - employees, high- & -0.102 & -0.022 & -0.160 & -0.206 & 0.226 & -0.542 \\
\hline qualification jobs & $(0.177)$ & $(0.244)$ & $(0.230)$ & $(0.379)$ & $(0.596)$ & $(0.495)$ \\
\hline \multirow[t]{2}{*}{ - self-employed } & $-0.415^{*}$ & -0.292 & $-0.503^{*}$ & -0.486 & -0.205 & -0.714 \\
\hline & $(0.189)$ & $(0.264)$ & $(0.246)$ & $(0.411)$ & $(0.618)$ & $(0.562)$ \\
\hline - employees, intermediate & -0.340 & -0.257 & -0.367 & -0.492 & -0.094 & -0.824 \\
\hline qualification jobs & $(0.184)$ & $(0.254)$ & $(0.242)$ & $(0.395)$ & $(0.602)$ & $(0.535)$ \\
\hline - employees, low-qualification & $-0.701^{\dagger}$ & -0.560 & $-0.785^{\dagger}$ & -0.191 & 0.152 & -0.507 \\
\hline jobs & $(0.220)$ & $(0.311)$ & $(0.296)$ & $(0.453)$ & $(0.714)$ & $(0.595)$ \\
\hline - crafts masters, skilled & $-0.982^{\dagger}$ & $-0.822^{\dagger}$ & $-1.083^{\dagger}$ & $-0.847 *$ & -0.756 & -1.000 \\
\hline workers & $(0.191)$ & $(0.264)$ & $(0.252)$ & $(0.384)$ & $(0.580)$ & $(0.526)$ \\
\hline \multirow[t]{2}{*}{ - un-/semi-skilled workers } & $-1.162^{\dagger}$ & $-0.916^{\dagger}$ & $-1.338^{\dagger}$ & $-1.329^{\dagger}$ & -0.745 & $-1.742^{\dagger}$ \\
\hline & $(0.209)$ & $(0.290)$ & $(0.275)$ & $(0.482)$ & $(0.764)$ & $(0.650)$ \\
\hline \multirow[t]{2}{*}{ - inactive, unemployed } & $-0.763^{+}$ & -0.558 & $-0.860^{\dagger}$ & $-1.047 *$ & -0.965 & -1.135 \\
\hline & $(0.225)$ & $(0.314)$ & $(0.298)$ & $(0.438)$ & $(0.646)$ & $(0.617)$ \\
\hline \multirow{2}{*}{$\begin{array}{l}\text { P: Highest occupational status } \\
\text { (ISEI/10) }\end{array}$} & $0.103^{\dagger}$ & $0.112^{*}$ & $0.095^{*}$ & $0.121^{*}$ & 0.071 & 0.151 \\
\hline & $(0.032)$ & $(0.046)$ & $(0.043)$ & $(0.059)$ & $(0.093)$ & $(0.079)$ \\
\hline \multirow{2}{*}{$\begin{array}{l}\text { P: Family disposable income, } \\
\text { R aged 11-20 ( } 1=\text { median })\end{array}$} & 0.176 & $0.335^{*}$ & 0.063 & $0.623^{*}$ & $1.207^{\dagger}$ & 0.244 \\
\hline & $(0.115)$ & $(0.166)$ & $(0.152)$ & $(0.271)$ & $(0.461)$ & $(0.339)$ \\
\hline \multirow{2}{*}{$\begin{array}{l}\text { P: Fraction of years R living } \\
\text { with both parents (ages 6-18) }\end{array}$} & $0.490^{\dagger}$ & $0.591 *$ & 0.390 & $0.596^{*}$ & 0.772 & 0.558 \\
\hline & $(0.162)$ & $(0.231)$ & $(0.219)$ & $(0.289)$ & $(0.492)$ & $(0.362)$ \\
\hline \multirow[t]{2}{*}{ R: N siblings } & 0.008 & 0.001 & 0.019 & 0.009 & 0.013 & 0.031 \\
\hline & $(0.027)$ & $(0.039)$ & $(0.037)$ & $(0.069)$ & $(0.094)$ & $(0.094)$ \\
\hline \multirow[t]{2}{*}{ R: Parity status } & $-0.174^{\dagger}$ & -0.095 & $-0.249^{\dagger}$ & $-0.316^{\dagger}$ & $-0.327^{*}$ & $-0.337^{*}$ \\
\hline & $(0.037)$ & $(0.054)$ & $(0.051)$ & $(0.100)$ & $(0.143)$ & $(0.145)$ \\
\hline \multirow[t]{2}{*}{ R: first-generation migrant } & -0.152 & 0.045 & -0.330 & -1.083 & -1.612 & -0.600 \\
\hline & $(0.130)$ & $(0.179)$ & $(0.182)$ & $(1.180)$ & $(2.294)$ & $(0.950)$ \\
\hline \multirow[t]{2}{*}{ R: second-generation migrant } & $0.315^{\dagger}$ & $0.323^{*}$ & $0.313^{*}$ & -0.558 & -0.826 & -0.351 \\
\hline & $(0.100)$ & $(0.144)$ & $(0.130)$ & $(0.409)$ & $(0.502)$ & $(0.560)$ \\
\hline \multirow[t]{2}{*}{ Constant } & -0.541 & $-1.832^{+}$ & -0.296 & -1.308 & -1.513 & -0.913 \\
\hline & $(0.315)$ & $(0.420)$ & $(0.384)$ & $(0.717)$ & $(0.879)$ & $(0.890)$ \\
\hline Model $\chi^{2}$ & $1,034.0^{\dagger}$ & $528.6^{+}$ & $583.1^{+}$ & $281.3^{+}$ & $156.3^{+}$ & $137.2^{+}$ \\
\hline Model df & 73 & 47 & 47 & 61 & 41 & 41 \\
\hline Log-likelihood & $-2,734.0$ & $-1,275.2$ & $-1,447.9$ & -657.9 & -297.3 & -353.6 \\
\hline Pseudo- $R^{2}$ & 0.224 & 0.232 & 0.219 & 0.228 & 0.267 & 0.197 \\
\hline $\mathrm{N}$ & 5,161 & 2,414 & 2,747 & 1,243 & 585 & 658 \\
\hline
\end{tabular}

Notes: G: grandparents (G1); P: parents (G2); R: respondent (G3). Regression model C from Table 1. All models control for full gender and birth cohort interactions.

Cluster-corrected standard errors in parentheses; $\uparrow p<0.01 ; * p<0.05$. Source: GSOEP 1984-2013. 
parents have been downwardly or upwardly mobile relative to their own parents (i.e., relative to the $\mathrm{G} 1$ generation), this provides an informative empirical test for either resource compensation or cumulative advantage. If current (G3) generation respondents from downwardly mobile parents are more successful in schools than other students at the same level of parental (G2) education, this means that grandparents are able to provide compensating resources that support respondents' (G3) educational attainment. And, if current (G3) generation respondents from upwardly mobile parents are less successful in schools than other students at the same level of parental (G2) education, this means that respondents benefit from dynastic cultural capital and mutually reinforcing advantages in an education-rich family environment.

Much as in other Western countries, education expanded dramatically in both parts of Germany over the twentieth century. Empirically, upward mobility between the grandparent (G1) and parent (G2) generation is therefore much more prevalent than downward educational mobility in both East and West Germany. Overall, 50 percent of West German parents have been upwardly mobile in terms of educational attainment relative to the grandparent generation and, with educational expansion occurring a decade earlier in East Germany, even slightly more than 60 percent of parents in East Germany. In the other direction, around one in six parents in East Germany has attained a lower level of education than the grandparent generation, and about one in eight parents did so in West Germany. Of course, G1-G2 educational mobility is correlated with parental (G2) educational outcomes. As Figure 1 shows, downwardly mobile parents mostly end up in the nonacademic tracks of the German educational system (HS/RS and VT, respectively), while upwardly mobile parents actually are in the majority among parents who obtained a degree in the academic tracks of the system (ABI and UNI in Figure 1). In both East and West Germany, more than 60 percent of parents with an academic-track degreeeither an upper secondary Abitur degree or, in most cases, a tertiary education degree-have been upwardly mobile relative to the nonacademic level of education in their (G1) family of origin. At the other end of the educational distribution, slightly less than 20 percent of parents with completed vocational training (the dominant nonacademic outcome in both parts of Germany) in East Germany have been downwardly mobile relative to the educational level of their (G1) parents; in West Germany, the corresponding figure is not quite 10 percent. Furthermore, the group with the lowest educational qualifications (no vocational degree) has a share of about one quarter of (G2) parents who have been downwardly mobile relative to the educational attainment of their (G1) parents in West Germany, and there also is a certain proportion of downwardly mobile parents in the Abitur category without completed tertiary degree (ABI) in West Germany. ${ }^{10}$

Figure 2 provides first descriptive evidence that G1-G2 educational mobility in the parental generation is relevant for educational attainment in the current (G3) generation. More specifically, Figure 2 shows the probability of obtaining an Abitur degree by the combined G1-G2 pattern of educational attainment in respondents' family of origin. Using a binary indicator for whether (grand)parents already completed the Abitur, Figure 2 shows two key facts: first, parental (G2) education matters strongly for respondents' (G3) attainment, irrespective of grandparent 


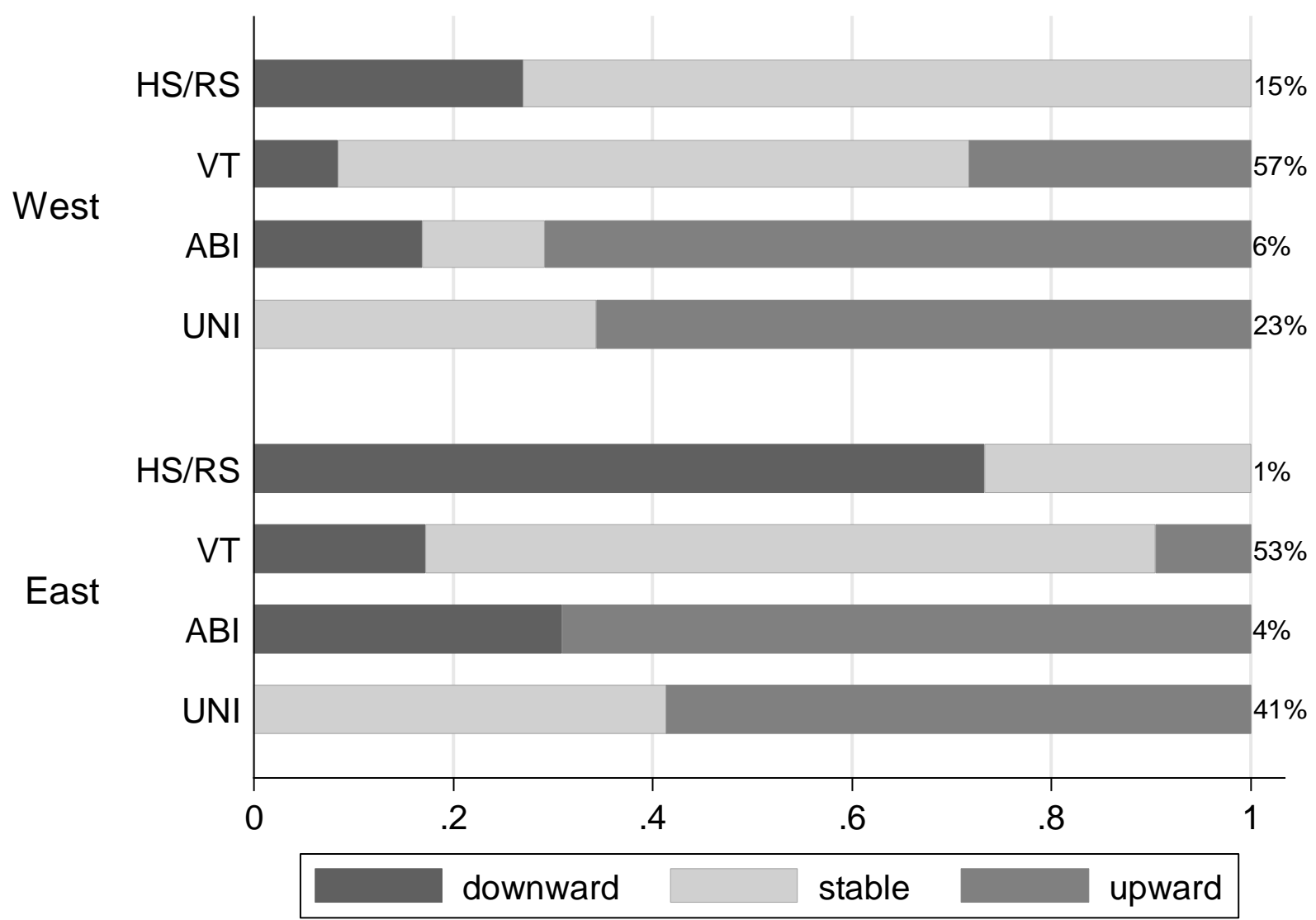

Figure 1: Educational attainment and educational (G1-G2) mobility in the parental generation in Germany, birth cohorts 1967-1992. Notes: parental level of education given as HS/RS: completed at most intermediate secondary education (Hauptschule or Realschule) degree; VT: completed vocational training; ABI: completed upper secondary education (Abitur) degree; UNI: completed tertiary degree. Shaded bar areas represent the distribution of parents' (G1-G2) educational mobility status within each level of parental (G2) education. Figures on the right-hand side of the bars provide the educational distribution in the parental (G2) generation separately for East and West German respondents (figures rounded). Source: GSOEP 1984-2013.

(G1) education. The probability of attaining the Abitur is between 70 percent to 80 percent in the two rightmost groups in West Germany (G2 with at least upper secondary education) but only between 30 percent to 40 percent in the two other groups (G2 without upper secondary education; cf. Becker 2007 for similar earlier results based on German Life History Study data). And, despite being a socialist educational system up until German reunification, this contrast is actually quite similar among East German respondents. A second contrast is more interesting in the present context, however: within each level of parental (G2) education, current (G3) generation respondents from a highly educated G1 family also have a higher probability of completing upper secondary education. In West Germany, the difference is some 10 percentage points at both ends of 


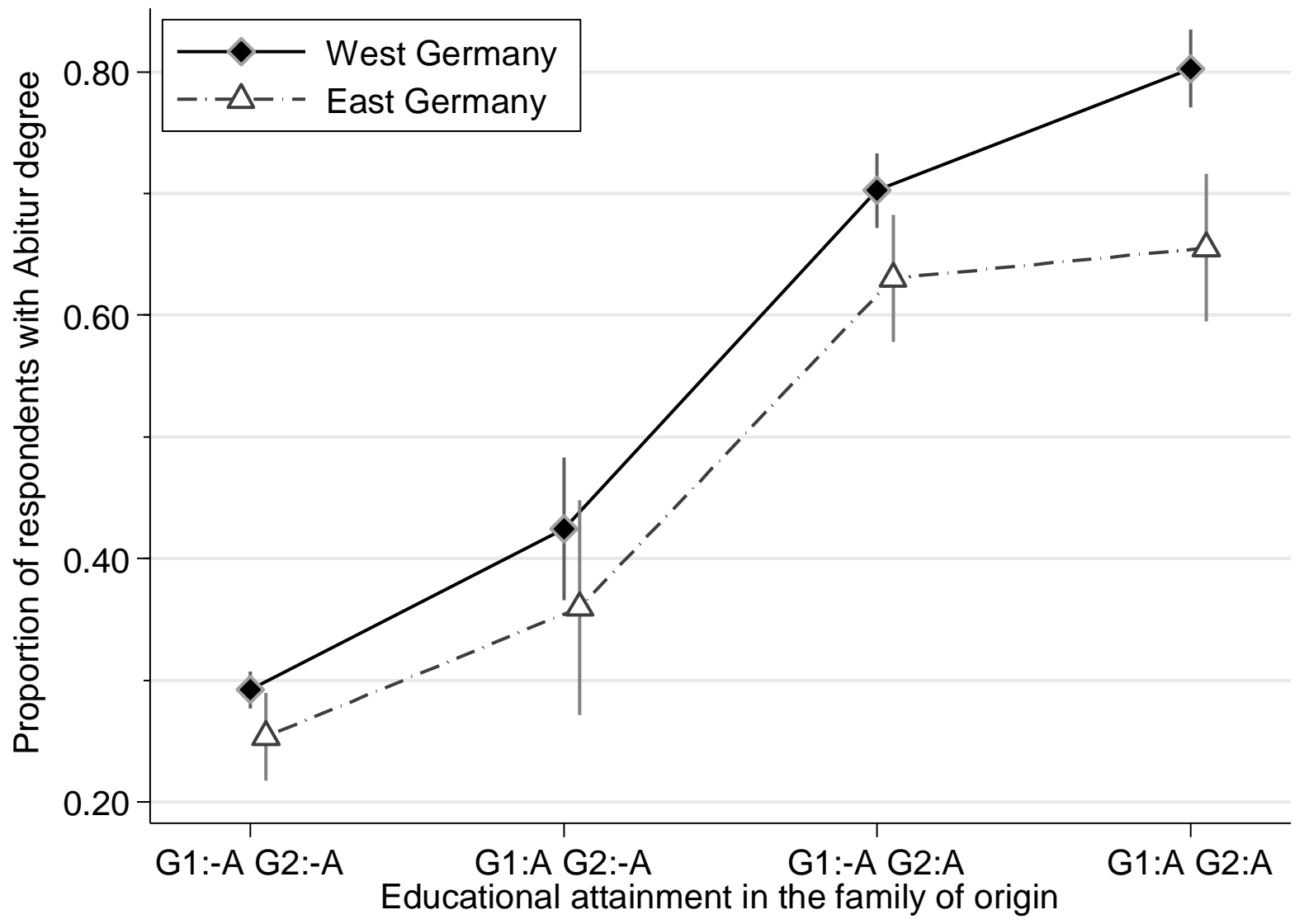

Figure 2: Persistence of educational attainment across three generations in Germany, birth cohorts 1967-1992. Notes: G1: grandparents; G2: parents; A/-A: at least one/no family member in G1/G2 generation holding an upper secondary (Abitur) degree. Whiskers represent 95\% confidence intervals around the probability estimate. Source: GSOEP 1984-2013.

the educational distribution, in East Germany, there is a similar 10-percentagepoint difference among non-academically trained (G2) parents but no observable difference at the upper educational end. Descriptively, this suggests the presence of both multigenerational resource compensation and cumulative cultural advantage in West Germany but resource compensation only among East German respondents.

I turn to regression modelling to test this descriptive finding more formally. The respective regression evidence is presented in Table 3, following the same setup as before. In contrast to the regression model used in Tables 1 and 2, however, I now utilize a relative measure of parental education that expresses the degree of parental (G2) educational mobility relative to the grandparent (G1) generation. Also, I distinguish between upward and downward parental educational mobility in order to permit a test of potential asymmetries in the effects of mobility: as was discussed before, the cumulative advantage mechanism implies the prediction of a negative effect of upward mobility (hypothesis 3), while the resource compensation mechanism predicts a positive effect of downward mobility in the parental (G2) 
Table 3: Persistence of educational attainment across three generations in Germany: cumulative advantage or resource compensation? Birth cohorts 1967-1992, logistic regression models.

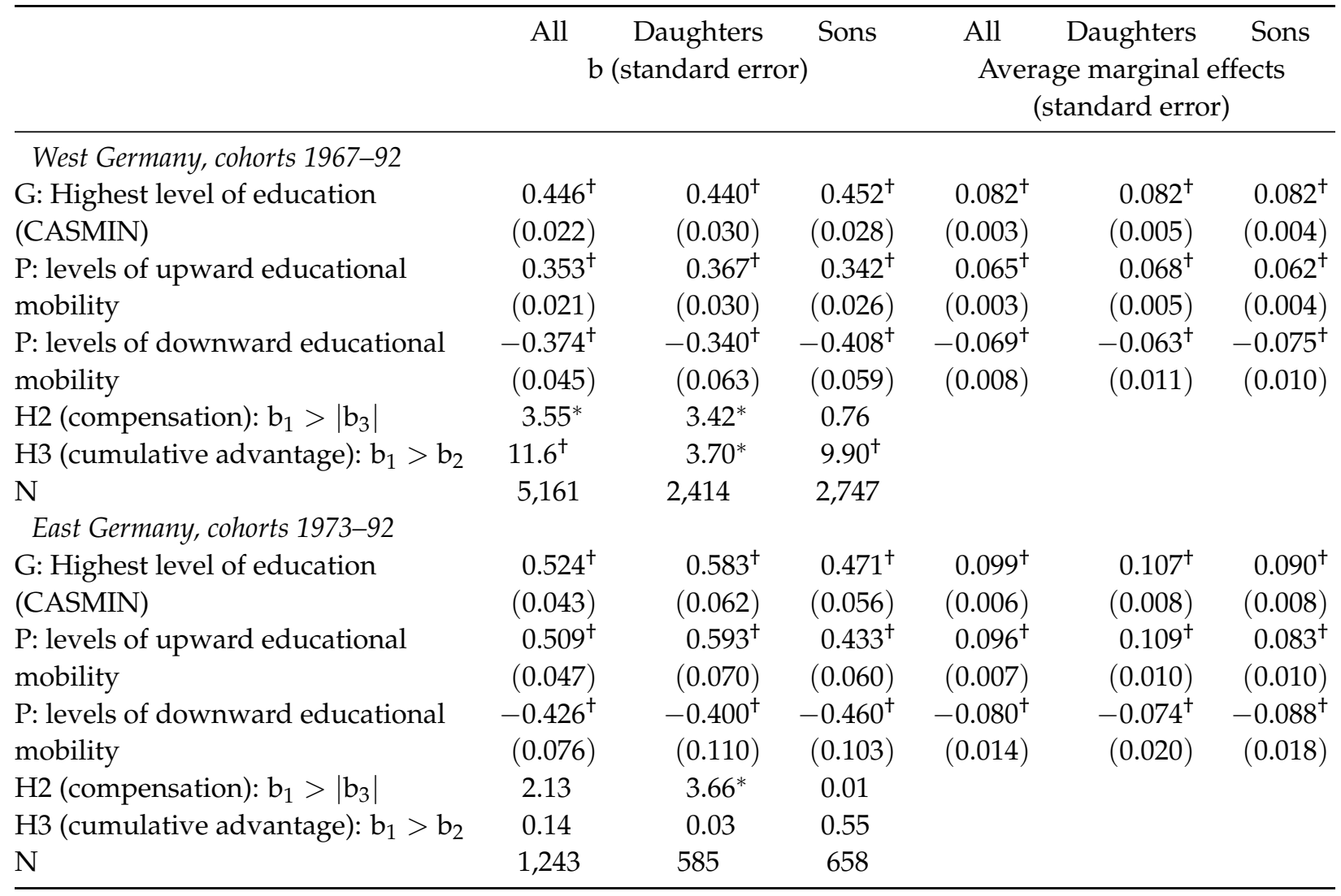

Notes: G: grandparents (G1); P: parents (G2). All models control for full gender and birth cohort interactions, parity and immigration status (equivalent to model B in Table 1).

Cluster-corrected standard errors in parentheses; $+p<0.01 ; * p<0.05$, results from one-sided tests for hypothesis 2 and hypothesis 3.

Source: GSOEP 1984-2013.

generation (hypothesis 2). The regression models of Table 3 test these predictions using the second (model B) specification from Table 1 -i.e., the regression model that includes measures of parental education (highest and mother's education) only. For West Germany, the results are little changed by using either variant of the two, net grandparent effect specifications (models B and C), yet for East Germany, the variant making smaller demands on the data seems preferable given the small sample size available for the analysis and the low statistical power that results from using the full covariate specification.

With this setup, the regression analyses broadly confirm the earlier conclusions from the descriptive data presented in Figure 2 before. For both hypotheses, the effect of grandparents' (G1) level of education provides the benchmark estimate. Given the fact that the model of Table 3 controls for both upward and downward educational mobility in the parental (G2) generation relative to the grandparent 
(G1) generation, the implicit reference category is parents who have not been educationally mobile relative to the grandparent generation. In Table 3, the coefficient for grandparent (G1) education therefore provides an estimate of the joint effect of grandparents' education and parents attaining the same level of education as their grandparents. For both East and West German respondents, this joint effect is sizeable, amounting to an AME of +8 percentage points per level of joint G1G2 education in West Germany and even +10 percentage points in East Germany. There are no gender differences in the effect size in West Germany, but the G1-G2 stable education effect is slightly larger among daughters than among sons in East Germany.

The hypothesis tests for resource compensation and cumulative cultural advantage now compare the effects of parental educational mobility on respondents' attainment relative to the benchmark of respondents' educational attainment in families of origin with stable (G1-G2) educational outcomes. Resource compensation (hypothesis 2) is present when the returns to G2 downward mobility are less than the benchmark: in this case, the current (G3) generation is to some degree protected from the negative implications of parents' (G2) educational attainment because their own attainment suffers less than if both the G1 and G2 generations had always been at the G2 level of education only. Cumulative cultural advantage (hypothesis 3) is present when the returns to G2 upward mobility are less than the benchmark: in this case, the current (G3) generation does not gain as much (in terms of their own educational opportunities) by parents' (G2) individual educational mobility than if both the G1 and G2 generations had always been at the G2 level of education already.

Empirically, the data provide clear support for the presence of both resource compensation and cumulative cultural advantage among West German families but (not surprisingly, given the absence of a main multigenerational effect in the analyses of the preceding section) tentative evidence only for the presence of some resource compensation in East Germany. For West Germany, the evidence is very clear and consistent. The (positive or negative) effects of parental (G2) educational mobility are always smaller than the benchmark estimate. The differences in AMEs are in the order of 1-1.5 percentage points and statistically significant at conventional levels. ${ }^{11}$ The only exception is the lack of evidence for any resource compensation among current (G3) generation West German men. In conclusion, there is clear evidence for cumulative cultural advantage among both sons and daughters in West Germany, but only daughters seem to benefit from multigenerational influence in the sense of resource compensation. Interestingly, the exact same conclusion on the relevance of resource compensation for daughters emerges in the East German data despite the fact that no multigenerational effects had been discernible overall. Yet, specifically for G3 daughters (but not for sons), there is evidence of resource compensation even in the East German sample. Compared to the benchmark estimate of an AME of +10 percentage points increase in the probability of attaining the Abitur, daughters in East Germany lose less from parental (G2) downward mobility in terms of their own educational opportunities. The AME is only at -7.5 percentage points per level of downward mobility, and the difference to the benchmark is statistically significant. There is no comparable evidence among East German men, and there 
also is no evidence for cumulative cultural advantage among either men or women in East Germany.

\section{Changes in Multigenerational Persistence in East Germany after German Reunification}

As a final step of the analysis, I explore whether there have been any changes in these multigenerational patterns of attainment in East Germany in the wake of German reunification. If the GDR's socialist education system has placed effective constraints on the abilities of families to foster their offspring's educational attainment, it is conceivable that family background effects have become stronger with the transition to an open educational system as characteristic for West Germany and other Western economies. To explore any immediate effects of this historic transition, I replicate all of the above analyses for the East German sample after dividing it further into the older group of birth cohorts 1973-82 and the younger half of the sample consisting of birth cohorts 1983-1992. As students enter secondary education between the ages 10 and 12 in both West and reunified Germany (but not in the former GDR), the latter group consists of all birth cohorts that entered secondary education after reunification in 1990. Given Germany's tracked educational system, the implication is that the younger cohort made one of the most decisive educational transitions (between enrolling in the academic-track Gymnasium or any other lower or intermediate secondary schooling options) already under post-reunification conditions.

Table 4 summarizes the results of the analysis. Not surprisingly, given the weak evidence for multigenerational attainment in the East German sample overall, there are few significant effects in either of the two subsamples, which are also becoming quite small. But even when taken as tentative evidence, one interesting gender difference emerges from this detailed analysis. Specifically, while there is little difference between the two periods in terms of the gross G1-G3 association (model A) or the net G1-G3 association (model B) controlling for parental education, it appears that some multigenerational influences have been present among sons prior to reunification but are now more present among daughters. The effect estimates in model B fail to reach any conventional level of statistical significance, but the detailed analysis of resource compensation versus cumulative advantage provides an interesting hint at a change in the multigenerational nature of attainment processes. In the birth cohorts prior to reunification, sons were benefitting from cumulative cultural advantage but not daughters. After reunification, the cumulative advantage among sons is gone, but a multigenerational pattern of G1 resource compensation in favor of daughters-but not sons-has emerged in East Germany.

\section{Summary and Conclusions}

The present analysis has added a case study of educational attainment in Germany to the burgeoning literature that has begun to examine multigenerational processes of status attainment. My results confirm and complement Hertel and 
Table 4: Persistence of educational attainment across three generations in East Germany before and after German reunification, birth cohorts 1973-1992, logistic regression models.

\begin{tabular}{|c|c|c|c|c|c|c|}
\hline & \multicolumn{3}{|c|}{ b (standard error) } & \multicolumn{3}{|c|}{$\begin{array}{l}\text { Average marginal effects } \\
\text { (standard error) }\end{array}$} \\
\hline & \multicolumn{6}{|c|}{ (A) Gross G1-G3 association, without G2 controls } \\
\hline Cohorts 1973-82 & $\begin{array}{c}0.171^{\dagger} \\
(0.036)\end{array}$ & $\begin{array}{r}0.190^{\dagger} \\
(0.053)\end{array}$ & $\begin{array}{r}0.154^{+} \\
(0.047)\end{array}$ & $\begin{array}{r}0.037^{+} \\
(0.007)\end{array}$ & $\begin{array}{r}0.042^{+} \\
(0.011)\end{array}$ & $\begin{array}{r}0.032^{+} \\
(0.009)\end{array}$ \\
\hline Cohorts 1983-92 & $\begin{array}{r}0.153^{\dagger} \\
(0.039)\end{array}$ & $\begin{array}{r}0.183^{+} \\
(0.055)\end{array}$ & $\begin{array}{r}0.131^{\dagger} \\
(0.052)\end{array}$ & $\begin{array}{r}0.035^{+} \\
(0.008)\end{array}$ & $\begin{array}{r}0.041^{+} \\
(0.012)\end{array}$ & $\begin{array}{r}0.030^{+} \\
(0.011)\end{array}$ \\
\hline & \multicolumn{6}{|c|}{ (B) Net G1-G3 association, controlling for G2 education } \\
\hline Cohorts 1973-82 & $\begin{array}{c}0.048 \\
(0.040)\end{array}$ & $\begin{array}{c}0.027 \\
(0.065)\end{array}$ & $\begin{array}{c}0.058 \\
(0.049)\end{array}$ & $\begin{array}{c}0.009 \\
(0.007)\end{array}$ & $\begin{array}{c}0.005 \\
(0.011)\end{array}$ & $\begin{array}{c}0.011 \\
(0.009)\end{array}$ \\
\hline Cohorts 1983-92 & $\begin{array}{c}0.034 \\
(0.044)\end{array}$ & $\begin{array}{c}0.085 \\
(0.063)\end{array}$ & $\begin{array}{c}-0.008 \\
(0.058)\end{array}$ & $\begin{array}{c}0.007 \\
(0.009)\end{array}$ & $\begin{array}{c}0.017 \\
(0.012)\end{array}$ & $\begin{array}{c}-0.002 \\
(0.011)\end{array}$ \\
\hline & \multicolumn{6}{|c|}{ (C) G1-G3 association as cumulative advantage vs. safety net } \\
\hline \multicolumn{7}{|l|}{ Cohorts 1973-82 } \\
\hline $\begin{array}{l}\text { G: Highest level of education } \\
\text { (CASMIN) }\end{array}$ & $\begin{array}{r}0.558^{\dagger} \\
(0.056)\end{array}$ & $\begin{array}{r}0.678^{+} \\
(0.092)\end{array}$ & $\begin{array}{r}0.463^{+} \\
(0.071)\end{array}$ & $\begin{array}{r}0.101^{+} \\
(0.007)\end{array}$ & $\begin{array}{r}0.115^{\dagger} \\
(0.010)\end{array}$ & $\begin{array}{r}0.086^{\dagger} \\
(0.010)\end{array}$ \\
\hline $\begin{array}{l}\text { P: levels of upward educational } \\
\text { mobility }\end{array}$ & $\begin{array}{r}0.485^{\dagger} \\
(0.058)\end{array}$ & $\begin{array}{r}0.653^{+} \\
(0.093)\end{array}$ & $\begin{array}{r}0.356^{+} \\
(0.073)\end{array}$ & $\begin{array}{r}0.088^{+} \\
(0.008)\end{array}$ & $\begin{array}{r}0.111^{+} \\
(0.011)\end{array}$ & $\begin{array}{r}0.066^{\dagger} \\
(0.012)\end{array}$ \\
\hline $\begin{array}{l}\text { P: levels of downward educational } \\
\text { mobility }\end{array}$ & $\begin{array}{r}-0.585^{\dagger} \\
(0.126)\end{array}$ & $\begin{array}{r}-0.627^{+} \\
(0.191)\end{array}$ & $\begin{array}{r}-0.559^{+} \\
(0.163)\end{array}$ & $\begin{array}{r}-0.106^{+} \\
(0.021)\end{array}$ & $\begin{array}{r}-0.107^{+} \\
(0.031)\end{array}$ & $\begin{array}{r}-0.104^{+} \\
(0.029)\end{array}$ \\
\hline $\mathrm{H} 2$ (compensation): $\mathrm{b}_{1}>\left|\mathrm{b}_{3}\right|$ & 0.06 & 0.09 & 0.41 & & & \\
\hline H3 (cumulative advantage): $b_{1}>b_{2}$ & 1.91 & 0.08 & $2.73^{*}$ & & & \\
\hline \multicolumn{7}{|l|}{ Cohorts 1983-92 } \\
\hline $\begin{array}{l}\text { G: Highest level of education } \\
\text { (CASMIN) }\end{array}$ & $\begin{array}{r}0.520^{+} \\
(0.064)\end{array}$ & $\begin{array}{r}0.535^{\dagger} \\
(0.090)\end{array}$ & $\begin{array}{r}0.510^{\dagger} \\
(0.085)\end{array}$ & $\begin{array}{r}0.101^{\dagger} \\
(0.009)\end{array}$ & $\begin{array}{c}0.104^{\dagger} \\
(0.014)\end{array}$ & $\begin{array}{r}0.099^{\dagger} \\
(0.012)\end{array}$ \\
\hline P: levels of upward educational mobility & $\begin{array}{r}0.578^{+} \\
(0.078)\end{array}$ & $\begin{array}{r}0.552^{+} \\
(0.107)\end{array}$ & $\begin{array}{r}0.587^{\dagger} \\
(0.108)\end{array}$ & $\begin{array}{r}0.113^{+} \\
(0.012)\end{array}$ & $\begin{array}{r}0.108^{+} \\
(0.017)\end{array}$ & $\begin{array}{r}0.114^{\dagger} \\
(0.017)\end{array}$ \\
\hline P: levels of downward educational mobility & $\begin{array}{r}-0.319^{+} \\
(0.097)\end{array}$ & $\begin{array}{r}-0.294^{*} \\
(0.143)\end{array}$ & $\begin{array}{r}-0.375^{+} \\
(0.132)\end{array}$ & $\begin{array}{r}-0.062^{+} \\
(0.018)\end{array}$ & $\begin{aligned}-0.057^{*} \\
(0.027)\end{aligned}$ & $\begin{array}{r}-0.073^{\dagger} \\
(0.024)\end{array}$ \\
\hline $\mathrm{H} 2$ (compensation): $\mathrm{b}_{1}>\left|\mathrm{b}_{3}\right|$ & $5.63^{+}$ & $4.34^{*}$ & 1.24 & & & \\
\hline H3 (cumulative advantage): $b_{1}>b_{2}$ & 0.80 & 0.03 & 0.85 & & & \\
\hline $\mathrm{N}$ & 543 & 256 & 287 & & & \\
\hline
\end{tabular}

Notes: G: grandparents (G1); P: parents (G2). All models control for full gender and birth cohort interactions, parity and immigration status (equivalent to models a and $\mathrm{b}$ in Table 1, respectively).

Cluster-corrected standard errors in parentheses; $t p<0.01 ; * p<0.05$, results from one-sided tests for hypothesis 2 and hypothesis 3.

Source: GSOEP 1984-2013. 
Groh-Samberg's (2014) recent study of class mobility by providing evidence of a multigenerational effect of grandparents' education on current generation educational outcomes in West Germany. My analysis also confirms earlier results of Fuchs and Sixt (2007a, 2007b) and Becker (2007), who obtained multigenerational effects on educational attainment among older birth cohorts in West Germany but had not fully noticed the broader theoretical implications of their results at the time. Going beyond any of the available studies, the present article has been the first to extend the analysis of multigenerational effects to East Germany and has also incorporated a first exploration of gender differences in the presence and source of multigenerational effects on attainment.

To shed light on the social mechanisms that generate multigenerational effects on status attainment, I distinguished between multigenerational resource compensation and cumulative cultural advantage, and I provided an empirical test for the presence of either mechanism in the data. For West Germany, I have been able to confirm the presence of both resource compensation and cumulative advantage in the empirical analysis. Indirectly, this evidence in fact offers an explanation for Hertel and Groh-Samberg's (2014) finding of stronger multigenerational attainment in either tail of the parental distribution in their analysis of class mobility in Germany: resource compensation is disproportionately relevant in the lower end of the parental status distribution, whereas cumulative cultural advantage generates multigenerational persistence in the upper tail of the parental status distribution, and combined they are able to potentially explain the pattern identified by Hertel and Groh-Samberg (2014). The distinction between resource compensation and cumulative cultural advantage might also provide a framework for thinking about possible cross-country differences in terms of where in the distribution multigenerational effects on attainment become important that are apparent in the recent studies of Jæger (2012), Pfeffer (2014), Hertel and Groh-Samberg (2014), and Wightman and Danziger (2014).

In that respect, the empirical findings from the intra-German regime contrast between the open educational system of West Germany and the state socialist educational system of the former GDR are of considerable interest. Empirically, the bivariate association between grandparents' education and respondents' educational outcomes is significantly weaker among East German families than in West Germany; also, unlike in West Germany, there is no evidence for multigenerational effects on educational attainment in East Germany at all once parental resources have been controlled for. As a result, extended family lineage has indeed been less consequential for respondents' educational attainment under the East German state socialist system than in West Germany's liberal society.

There is in fact an interesting gender aspect to these findings as well as to the larger analysis. Gender differences in the strength of multigenerational effects on attainment are small overall, but there is clear empirical evidence that grandparent resource compensation seems relevant only for daughters' attainment and not for sons'. This pattern is obvious in the West German data but has also emerged right after German reunification among respondents from younger birth cohorts in East Germany. Sons instead benefit more clearly from multigenerational effects of the cumulative cultural advantage type. Interestingly, cumulative cultural advantage 
among sons has been present even in the former GDR but had vanished with reunification. Daughters generally benefit less from such cumulative advantage effects, although the mechanism is also present to some limited degree among women in West Germany. These interesting gender-specific patterns could well suggest that a more differentiated analysis of gender-typified patterns of multigenerational influence along grandmother-granddaughter or grandfather-grandson dyads might hold additional promise in the German case, if not in other countries as well.

\section{Notes}

1 Children become GSOEP respondents at the age of 17 , so that the birth cohort 1967 is the oldest cohort of children that still lived in the parental home when the survey started in the mid-1980s. For the East German part of the survey started in 1990, the resulting cohort range is 1973-1992.

2 This assumes that respondents will benefit from educational resources available anywhere in the grandparent generation, an assumption that is supported by separate analyses showing independent and statistically significant effects of both average and maximum level of education in the grandparent (G1) generation. To simplify the interpretation of multigenerational associations, I decided to adopt a single indicator for G1 resources in the present analysis and therefore chose the single indicator with maximum explanatory as well as statistical power. I also pick the simple indicator of maximum educational attainment in the grandparent generation as my focal indicator because I do not intend to specifically theorize about or empirically test for differences in the relative strength of grandparent influence along either the matrilineal or the patrilineal family line, nor do I intend to propose a theory of or an empirical test for any sort of gender-typified patterns of multigenerational influence.

3 As a result, a value of 1 indicates that respondents grew up in a family in which average family income was exactly at the level of median income in Germany in their youth, whereas a value of 2 expresses that family financial resources were twice that level. After expressing all income data relative to the median, there also is no need to further adjust the data for inflation.

4 Additional controls for the particular federal state that respondents grew up in do not materially affect the results reported below.

5 Multiple imputation models also produce results that are very similar to those reported below.

6 The sample includes 5,161 West German respondents from birth cohorts 1967-1992 and 1,243 East German respondents born between 1973 and 1992 (cf. note 1).

7 Naturally, the interpretation of the residual (net) grandparent effect as a genuine (causal) multigenerational effect of grandparents on children's attainment rests on the usual qualifiers. The estimates reported below will overestimate any true causal grandparent effect in case of unobserved but relevant resources of the parent (G2) generation and in case of systematic measurement (reporting) error in educational information within families that will result in spurious G1-G3 associations of educational attainment. In the former case, at least, presenting two specifications of the mediation model that differ in terms of the range of parental (G2) generation covariates will provide readers with a sense of the degree of model uncertainty in the estimates and a robustness check for the overall conclusions drawn in this article. 
8 The dataset includes multiple siblings from the same G2 family as long as all sampling requirements are being met. For simplicity of interpretation, I nevertheless present estimates from standard logistic regression models because the results from logistic family random-effect models are very similar to those reported below. To account for the presence of multiple siblings from the same family, however, I rely on cluster-corrected standard errors for statistical inference.

9 I use the CASMIN scale as a linear metric throughout this article. Other than complicating the verbal presentation, the traditional categorical variable does not improve statistical model fit over the simpler linear scale according to the Bayesian Information Criterion (BIC). Moreover, all substantive conclusions of this article, including the results of the two subsequent sections, are unchanged when using the CASMIN scale as a categorical measure.

10 Due to small cell sizes, I refrain from interpreting the ABI and the HS/RS categories in East Germany.

11 Strictly speaking, as both hypothesis 2 and hypothesis 3 are directed hypotheses, onesided tests are actually appropriate for statistical inference in this particular case.

\section{References}

Becker, Gary S., and Nigel Tomes. 1986. "Human-Capital and the Rise and Fall of Families." Journal of Labor Economics 4(3):S1-S39. https : /doi . org/10 .1086/298118

Becker, Rolf. 2007. "Wie nachhaltig sind die Bildungsaufstiege wirklich? Eine Reanalyse der Studie von Fuchs und Sixt (2007) über die soziale Vererbung von Bildungserfolgen in der Generationenabfolge [How sustainable is the educational expansion actually? A reanalysis of the results by Fuchs and Sixt (2007) on the social inheritance of educational success over consecutive generations]." Kölner Zeitschrift für Soziologie und Sozialpsychologie 59(3):512-23. https : /doi .org/10.1007/s11577-007-0059-1

Blau, Peter M., and Otis D. Duncan. 1967. The American Occupational Structure. New York: Free Press.

Bol, Thijs, and Matthijs Kalmijn. 2016. "Grandparents' Resources and Grandchildren's Schooling: Does Grandparental Involvement Moderate the Grandparent Effect?" Social Science Research 55:155-70. https : /doi .org/10.1016/j .ssresearch. 2015.09.011

Bourdieu, Pierre. 1977. "Cultural Reproduction and Social Reproduction." Pp. 487-511 in Power and Ideology in Education, edited by Jerome Karabel and Albert H. Halsey. New York: Oxford University Press.

Braun, Michael, and Walter Müller. 1997. "Measurement of Education in Comparative Research." Comparative Social Research 16(1):163-201.

Brauns, Hildegard, and Susanne Steinmann. 1999. "Educational Reform in France, WestGermany and the United Kingdom: Updating the CASMIN Educational Classification." ZUMA-Nachrichten 44:7-44.

Chan, Tak Wing, and Vikki Boliver. 2013. "The Grandparents Effect in Social Mobility: Evidence from British Birth Cohort Studies." American Sociological Review 78(4):662-78. https:/doi.org/10.1177/0003122413489130

Chan, Tak Wing, and Vikki Boliver. 2014. "Social Mobility Over Three Generations in Finland: A Critique." European Sociological Review 30(1):13-17. https:/doi.org/10.1093/esr/ jct012 
DiPrete, Thomas A., and Gregory M. Eirich. 2006. "Cumulative Advantage as a Mechanism for Inequality: A Review of Theoretical and Empirical Developments." Annual Review of Sociology 32:271-97. https : /doi . org/10.1146/annurev . soc.32.061604.123127

Erola, Jani, and Pasi Moisio. 2007. "Social Mobility Over Three Generations in Finland, 19502000." European Sociological Review 23(2):169-83. https : /doi .org/10 . 1093/esr/ jc1027

Fuchs, Marek, and Michaela Sixt. 2007a. "Bildungsmobilität über drei Generationen. Was genau bewirken Bildungsaufstiege für die Kinder der Aufsteiger? Replik auf den Diskussionsbeitrag von Rolf Becker [Educational Mobility over Three Generations. Effects of Educational Climbing on the Climbers' Children. Response to a Discussion by Rolf Becker]." Kölner Zeitschrift für Soziologie und Sozialpsychologie 59(3):524-35. https:/doi.org/10.1007/s11577-007-0060-8

Fuchs, Marek, and Michaela Sixt. 2007b. "Zur Nachhaltigkeit von Bildungsaufstiegen [On the Sustainability of Educational Improvement. Social Heredity Transmission of Educational Success over Multiple Generations]." Kölner Zeitschrift für Soziologie und Sozialpsychologie 59(1):1-29. https:/doi .org/10.1007/s11577-007-0001-6

Ganzeboom, Harry B. G., and Donald J. Treiman. 1996. "Internationally Comparable Measures of Occupational Status for the 1988 International Standard Classification of Occupations." Social Science Research 25(3):201-39. https : /doi .org/10.1006/ssre.1996.0010

Geißler, Rainer. 1983. "Bildungschancen und Statusvererbung in der DDR [EducationalOpportunities and Inherited Social-Status in the German-Democratic-Republic]." Kölner Zeitschrift für Soziologie und Sozialpsychologie 35(4):755-70.

Geißler, Rainer. 1990. "Entwicklung der Sozialstruktur und Bildungswesen in der Bundesrepublik Deutschland und in der DDR [Trends in social stratification and education in the Federal Republic of Germany and in the GDR]." Pp. 83-111 in Vergleich von Bildung und Erziehung in der Bundesrepublik Deutschland und in der Deutschen Demokratischen Republik, edited by Oskar Anweiler. Köln: Verlag Wissenschaft und Politik.

Geißler, Rainer. 2011. Die Sozialstruktur Deutschlands. Zur gesellschaftlichen Entwicklung mit einer Bilanz zur Vereinigung [The social structure of Germany. Social trends and a summary of the reunification]. Wiesbaden: VS Verlag.

Hällsten, Martin. 2014. "Inequality Across Three and Four Generations in Egalitarian Sweden: 1st and 2nd Cousin Correlations in Socio-Economic Outcomes." Research in Social Stratification and Mobility 35:19-33. https:/doi .org/10.1016/j.rssm.2013.09.002

Hertel, Florian R., and Olaf Groh-Samberg. 2014. "Class Mobility Across Three Generations in the U.S. and Germany." Research in Social Stratification and Mobility 35:35-52. https: /doi.org/10.1016/j.rssm.2013.09.007

Huinink, Johannes, and Heike Solga. 1994. "Occupational Opportunities in the GDR: A Privilege of the Older Generations?" Zeitschrift für Soziologie 23(3):237-53. https:/doi . org/10.1515/zfsoz-1994-0304

Jæger, Mads M. 2012. "The Extended Family and Children's Educational Success." American Sociological Review 77(6):903-22. https : /doi .org/10.1177/0003122412464040

Jencks, Christopher, Marshall Smith, Henry Acland, Mary Jo Bane, David Cohen, Herbert Gintis, Barbara Heyns, and Stephan Michelson. 1972. Inequality: A Reassessment of the Effect of Family and Schooling in America. New York: Basic Books.

Lindahl, Mikael, Marten Palme, Sofia Sandgren Massih, and Anna Sjögren. 2015. "LongTerm Intergenerational Persistence of Human Capital An Empirical Analysis of Four Generations." Journal of Human Resources 50(1):1-33. https : / doi . org/10 . 1353/jhr . 2015. 0000 
Mare, Robert D. 2011. "A Multigenerational View of Inequality." Demography 48(1):1-23. https:/doi.org/10.1007/s13524-011-0014-7

Mare, Robert D. 2014. "Multigenerational Aspects of Social Stratification: Issues for Further Research." Research in Social Stratification and Mobility 35:121-28. https:/doi .org/10. 1016/j.rssm.2014.01.004

Mare, Robert D. 2015. "Measuring Networks beyond the Origin Family." Annals of the American Academy of Political and Social Science 657(1):97-107. https: /doi .org/10.1177/ 0002716214548410

Mayer, Karl Ulrich, and Heike Solga. 1994. "Mobilität und Legitimität: zum Vergleich der Chancenstrukturen in der alten DDR und der alten BRD oder: Haben Mobilitätschancen zum Zusammenbruch der DDR beigetragen? [Mobility and Legitimacy - A Comparison of the Opportunity Structures in East and West-Germany or - Did Mobility Chances Contribute to the Stability and Collapse of the Former GDR]." Kölner Zeitschrift für Soziologie und Sozialpsychologie 46(2):193-208.

Modin, Bitte, Robert Erikson, and Denny Vagero. 2013. "Intergenerational Continuity in School Performance: Do Grandparents Matter?" European Sociological Review 29(4):858-70. https:/doi.org/10.1093/esr/jcs064

Møllegaard, Stine, and Mads M. Jæger. 2015. "The Effect of Grandparents' Economic, Cultural, and Social Capital on Grandchildren's Educational Success." Research in Social Stratification and Mobility 42:11-19. https : /doi .org/10.1016/j .rssm. 2015.06.004

Pfeffer, Fabian T. 2011. "Status Attainment and Wealth in the United States and Germany." Pp. 109-37 in Persistence, Privilege, and Parenting. The Comparative Study of Intergenerational Mobility., edited by Timothy M. Smeeding, Robert Erikson, and Markus Jäntti. New York: Russell Sage Foundation.

Pfeffer, Fabian T. 2014. "Multigenerational Approaches to Social Mobility. A Multifaceted Research Agenda." Research in Social Stratification and Mobility 35:1-12. https:/doi .org/ 10.1016/j.rssm.2014.01.001

Solon, Gary. 2014. "Theoretical Models of Inequality Transmission Across Multiple Generations." Research in Social Stratification and Mobility 35:13-18. https:/doi .org/10.1016/j . rssm.2013.09.005

Wagner, Gert G., Joachim R. Frick, and Jürgen Schupp. 2007. "The German Socio-Economic Panel Study (SOEP) - Scope, Evolution and Enhancements." Schmollers Jahrbuch 127(1):13969. https:/doi.org/10.2139/ssrn. 1028709

Warren, John R., and Robert M. Hauser. 1997. "Social Stratification Across Three Generations: New Evidence From the Wisconsin Longitudinal Study." American Sociological Review 62(4):561-72. https : /doi .org/10.2307/2657426

Wightman, Patrick, and Sheldon Danziger. 2014. "Multi-Generational Income Disadvantage and the Educational Attainment of Young Adults." Research in Social Stratification and Mobility 35:53-69. https:/doi .org/10.1016/j.rssm.2013.09.004

Zeng, Zhen, and Yu Xie. 2014. "The Effects of Grandparents on Children's Schooling: Evidence From Rural China." Demography 51(2):599-617. https:/doi.org/10.1007/ s13524-013-0275-4 
Acknowledgements: The data from the German Socio-Economic Panel survey have kindly been made available by the German Institute for Economic Research (DIW), Berlin. DIW bears no responsibility for the uses made of the data in the analyses reported in the present manuscript. This research has been supported by a research grant from the German Science Foundation (DFG) to the author for her project, "Family background and women's changing life courses" (ZI 1495/1-1). I thank Markus Gangl for valuable comments on my work.

Andrea Ziefle: School of Social Sciences (FB03), Goethe-University Frankfurt am Main. E-mail: aziefle@soz.uni-frankfurt.de. 